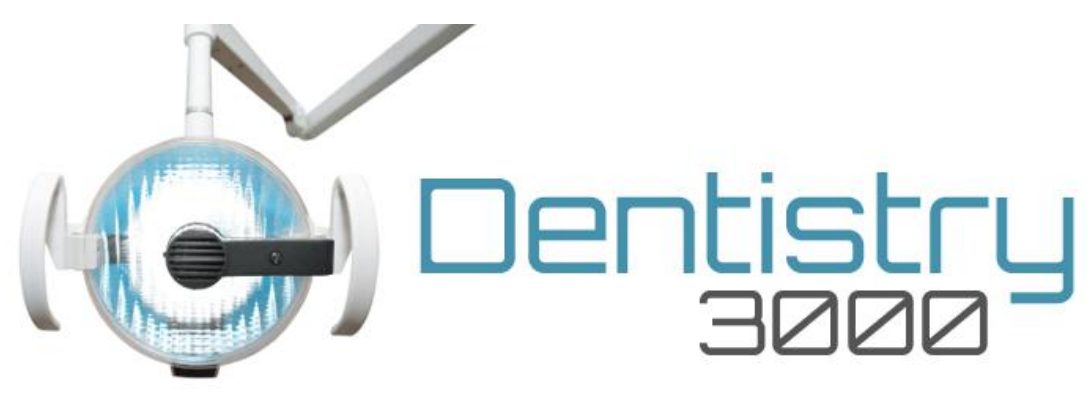

\title{
Errata for "Lack of association between IRF6 polymorphisms and nonsyndromic oral clefts in South Indian population," Volume 1, No 1
}

Dentistry 3000

ISSN: 2167-8677 (online)

This page reflects errors that were found in the article "Lack of association between IRF6 polymorphisms and nonsyndromic oral clefts in South Indian population," Volume 1, No 1 of Dentistry 3000.

1. Gurramkonda, Venkatesh, Jyotsna Murthy, Altaf Hussain Syed, \& Bhaskar VKS Lakkakula. "Lack of association between IRF6 polymorphisms and nonsyndromic oral clefts in South Indian population." Dentistry 3000 [Online], 1.1 (2013): n. pag. Web. 3 Sep. 2013

The article title should be "Evidence of association between IRF6 polymorphisms and nonsyndromic oral clefts in South Indian population."

Last updated Wednesday, September 4, 2013 